\title{
AGE RELATED HEARING LOSS IN SMOKERS AND NON-SMOKERS
}

\author{
P. Pratima1 ${ }^{1}$ M. Padma Geethanjali², M. Usha Rani ${ }^{3}$.
}

\section{HOW TO CITE THIS ARTICLE:}

P. Pratima, M. Padma Geethanjali, M. Usha Rani. "Age related hearing loss in smokers and non-smokers". Journal of Evolution of Medical and Dental Sciences 2013; Vol2, Issue 28, July 15; Page: 5059-5065.

\begin{abstract}
The present study comprises of 100 men and women. 52 males and 48 females within the age group from 40 years to 80 years were selected. Patients attending ENT OPD above 40 years without any comorbidity and having clinical features of age related hearing loss such as difficulties in hearing conversations, tinnitus, hearing loss, were selected. Patients with ear discharge, ototoxicity, ear surgery, cardiovascular disease, exposure to noise were excluded. Smoking status at the time of the baseline hearing examination was determined by self-report. Subjects who were smoking at the time of the examination were regarded as current smokers, Subjects who had smoked previously but had ceased at the time of examination were regarded as past smokers, and Subjects who had never smoked were regarded as non-smokers. The present study is undertaken with the aim to assess any association between smoking and age related hearing loss, to know whether the hearing impairment is more prevalent in smokers or non-smokers, to know in which age group the percentage of hearing impairment is more prevalent, and to know which ear is more affected in smokers and non-smokers group. Hearing tests were performed in a sealed, soundproof room. The examination included an otoscopic evaluation, pure-tone air-conduction and boneconduction audiometry. Average threshold of hearing was taken and greater than $25 \mathrm{~dB}$ was used as an indicator of hearing loss. In the present study, the results are consistent with early clinical studies reporting that smoking is significantly associated with hearing loss. Modification of life style factors (smoking cessation) can retard the age related changes in hearing sensitivity. The Health education through various types of electronic media, seminars, and cinemas about smoking cessation should be undertaken.
\end{abstract}

KEY WORDS: Age related hearing loss, Smokers, Non smokers.

INTRODUCTION: Hearing impairment is the most frequent sensory deficit in human populations, affecting more than 250 million people in the world. It is defined as a pure-tone average (PTA) of thresholds at 500,1000, 2000, and $4000 \mathrm{~Hz}$ greater than $25-\mathrm{dB}$ hearing level (dB HL) in the better ear.The leading causes of adult-onset hearing loss are Presbycusis (Age related hearing loss) followed by Noise-induced hearing loss.The most common form of hearing impairment in humans is Age-related hearing loss.

Age-related hearing loss is characterized by bilateral high-frequency hearing loss resulting from degeneration of cochlear structures within the inner ear. Both genetic and environmental factors contribute to ARHL (Age related hearing loss). Although age is the strongest predictor for developing ARHL, other known risk factors for ARHL include male sex, family history of hearing loss, occupational and recreational noise exposure, type 2 diabetes mellitus, and smoking. Impairment in mitochondrial function due to mutations in the mitochondrial genome (mtDNA) is associated with an insidious decline in physiologic and biochemical performance that contributes to 
the aging process. The mechanisms by which smoking may cause hearing loss are not entirely known.

Smoking negatively affects the cochlear artery by elevating carbon monoxide and nicotine levels in the blood. High carbon monoxide and nicotine levels may contract blood vessels or cause vasospasm and thrombotic occlusion. Smoking may cause hearing loss at high frequencies by impairing the vascular system in the cochlear artery. Another possible mechanism is that smoking may increase blood viscosity and damage sensory cells.

MATERIALS AND METHODS: The study population comprised a total of 100 men and women aged 40-80 years who underwent hearing tests. A questionnaire about ear and hearing-related medical history, noise exposure during leisure, military service, and work; and self-perceived hearing function were administered as an interview.

Hearing tests were performed in a sealed, soundproof room. The examination included an otoscopic evaluation, pure-tone air-conduction and bone-conduction audiometry. Audiometric testing was conducted according to the guidelines of the American Speech-Language-Hearing Association using clinical audiometers equipped with TDH-50 earphones. Insert earphones and masking were used as necessary.

Pure-tone air-conduction thresholds were obtained for each ear at 250, 500, 1000, 2000, 3000, 4000, 6000, and $8000 \mathrm{~Hz}$. Bone-conduction thresholds were measured at only 2 frequencies (500 and $4000 \mathrm{~Hz}$ ) because of time constraints. Average threshold of hearing was taken and greater than $25 \mathrm{~dB}$ was used as an indicator of hearing loss.

METHOD OF COLLECTION OF DATA : 1 . Patients attending ENT OPD above 40 years age without any comorbidities and having clinical features of age related hearing loss such as difficulties in hearing conversations, Tinnitus, Hearing loss, were selected .

2. Patients with ear discharge, ototoxicity, ear surgery, cardiovascular disease, exposure to noise were excluded. 3. Analyses were conducted using SPSS.16 software. Independent Student t tests were applied for calculating differences in means for continuous data.

PURE TONE AUDIOMETRY: An audiometer is an electronic device which produces pure tones, the intensity of which can be increased or decreased in $5 \mathrm{~dB}$ steps. When an object vibrates in fixed single frequency the sound waves will present a sinusoidal wave pattern called sine-wave. The sound sensation produced by such a sine-wave is called a pure tone sound. In pure tone audiometry we test the hearing sensitivity of a subject. The sounds that we hear in nature are complex sounds and not pure tone sounds. It is the key hearing test used to identify hearing threshold levels of an individual, enabling determination of the degree, type and configuration of a hearing loss. Thus, providing the basis for diagnosis and management.

PTA provides ear specific thresholds, and uses frequency specific pure tones to give place specific responses, so that the configuration of a hearing loss can be identified. As PTA uses both air and bone conduction audiometry, the type of loss can also be identified via the air-bone gap. Audiometry is a subjective test -- it is not an objective measurement. It depends on people pushing a button or raising their hand, when they hear a tone. 
The threshold of hearing is defined as "the level of a sound at which, under specified conditions, a person gives $50 \%$ of correct detection responses on repeated trails. Specified conditions mean the type of sound and ways of presenting the test sound. The normal test sound is pure tone pulses at standardized frequencies in the range of $125-8000 \mathrm{~Hz}$ and the normal presentation mode is manually by means of a standardized type of ear. The most commonly used ear phone type is the supra-aural Telephone TDH -39 and its later versions Telephone TDH -49 and 50 .

Air conduction thresholds are marked on the audiogram with an "o" for the right ear and an " $\mathbf{x}$ " for the left ear. Bone conduction thresholds are obtained using a small vibrator placed on the forehead or on the mastoid bone. Thresholds are typically indicated on the audiogram with the symbols "<" “>" (unmasked) or "[" "]" (masked). Because the skull vibrates as a whole, bone conduction thresholds primarily reflect the contribution of the inner ear, mostly bypassing the function of the outer and middle ear. The comparison of Air conduction thresholds and bone conduction thresholds provides an initial differentiation between conductive, mixed and sensorineural involvement. Sensorineural hearing loss is characterized by equivalent air and bone conduction (i.e. air -bone gap of less than $10 \mathrm{~dB}$ ). Conductive hearing loss is characterized by bone conduction thresholds within normal limits, with a concurrent gap between the poorer air conduction and bone conduction thresholds of at least $10 \mathrm{~dB}$. A mixed hearing loss contains air-bone gaps with the bone conduction thresholds outside of the normal range. Both air and bone conduction thresholds may be obtained using an approach that ascends or descends in intensity but are typically determined using a bracketing technique.

\section{Symbols used in audiogram charting}

\begin{tabular}{|l|l|l|}
\hline \multicolumn{1}{|c|}{ Modality } & Right Ear & Left Ear \\
\hline AC unmasked & \\
\hline AC masked & & \\
\hline BC unmasked & & \\
\hline BC masked &
\end{tabular}

\section{Degree of Hearing Loss (WHO Classification)}

WHO (1980) recommended the following classification on the basis of pure tone audiogram taking the average of thresholds of hearing for frequencies of 500,1000 and $2000 \mathrm{~Hz}$ with reference to ISO: R.389-1970(international calibration of audiometers). 


\section{ORIGINAL ARTICLE}

\begin{tabular}{|l|l|l|}
\hline $\begin{array}{l}\text { Grade of } \\
\text { impairment }\end{array}$ & $\begin{array}{l}\text { Audiometric ISO value (average of } \\
500,1000,2000, \\
4000 \mathrm{~Hz})\end{array}$ & \multicolumn{1}{|c|}{ Impairment description } \\
\hline 0 (no impairment) & $25 \mathrm{~dB}$ HL or less(better ear) & $\begin{array}{l}\text { No or very slight hearing problems. Able to } \\
\text { hear whispers }\end{array}$ \\
\hline $\begin{array}{l}1 \text { (Slight } \\
\text { impairment) }\end{array}$ & $\begin{array}{l}\text { Able to hear and repeat words spoken in } \\
\text { normal voice at 1 metre }\end{array}$ \\
\hline $\begin{array}{l}2 \text { (Moderate } \\
\text { impairment) }\end{array}$ & $\begin{array}{l}\text { Able to hear and repeat words using raised } \\
\text { voice at 1 metre }\end{array}$ \\
\hline $\begin{array}{l}3 \text { (severe } \\
\text { impairment) }\end{array}$ & $61-80 \mathrm{~dB}$ HL (better ear) & $\begin{array}{l}\text { Able to hear some words when shouted into } \\
\text { better ear }\end{array}$ \\
\hline $\begin{array}{l}4 \text { (Profound } \\
\text { impairment } \\
\text { including deafness) }\end{array}$ & $81 \mathrm{~dB}$ HL or greater (better ear) & $\begin{array}{l}\text { Unable to hear and understand even a } \\
\text { shouted voice }\end{array}$ \\
\hline
\end{tabular}

Government of India has recommended the classification based on percentage of hearing impairment.

Recommended classification

\begin{tabular}{|l|l|l|l|l|}
\hline $\begin{array}{l}\text { Sl. } \\
\text { no. }\end{array}$ & Category & Type of impairment & DB level & $\begin{array}{l}\text { Percentage of Hearing } \\
\text { Impairment }\end{array}$ \\
\hline 1 & I & Mild Hearing impairment & $26-40 \mathrm{dBHI}$ in better ear & Less than $40 \%$ \\
\hline 2 & II & Moderate HI & $41-55 \mathrm{~dB}$ HI in better ear & $40 \%$ to $50 \%$ \\
\hline 3 & III & Severe HI & 56 to $70 \mathrm{~dB}$ HI in better ear & $50 \%$ to $75 \%$ \\
\hline 4 & IV & Total deafness & No hearing & $100 \%$ \\
\hline & & Near total deafness & $\begin{array}{l}91 \mathrm{~dB} \text { and above in better } \\
\text { ear }\end{array}$ & $100 \%$ \\
\hline & & Profound hearing impairment & $71-90 \mathrm{~dB}$ & $75-100 \%$ \\
\hline
\end{tabular}

\section{RESULTS:}

Distribution of Study population according to Age\& Sex

\begin{tabular}{|l|r|c|c|l|c|c|c|}
\hline \multicolumn{5}{|c|}{ SMOKERS } & \multicolumn{5}{c|}{ NONSMOKERS } \\
\hline Age group(yrs) & Male & Female & Total & Age group(yrs) & Male & Female & Total \\
\cline { 1 - 9 } & $70-50$ & 0 & 7 & $40-50$ & 3 & 10 & 13 \\
\hline $51-60$ & 9 & 9 & 18 & $51-60$ & 8 & 12 & 20 \\
\hline $61-70$ & 14 & 10 & 24 & $61-70$ & 6 & 6 & 12 \\
\hline $71-80$ & 1 & 0 & 1 & $71-80$ & 4 & 1 & 5 \\
\cline { 6 - 9 } & & & 50 & & & & 50 \\
\hline
\end{tabular}




\section{ORIGINAL ARTICLE}

On doing student $t$ test:

\begin{tabular}{|l|l|c|c|c|c|}
\hline & Group name & N & Mean & Std. Deviation & $\begin{array}{c}\text { Std. Error } \\
\text { Mean }\end{array}$ \\
\hline $\begin{array}{l}\text { Right Ear Hearing } \\
\text { Impairment (HI) }\end{array}$ & Smokers & 50 & 47.4400 & 22.06499 & 3.12046 \\
\cline { 2 - 6 } & $\begin{array}{l}\text { Non } \\
\text { smokers }\end{array}$ & 50 & 27.1000 & 20.29100 & 2.86958 \\
\hline
\end{tabular}

Independent Samples Test

\begin{tabular}{|l|c|c|c|c|}
\hline & \multicolumn{4}{|c|}{ t-test for Equality of Means } \\
\cline { 2 - 5 } & & & & $\begin{array}{c}\text { Std. Error } \\
\text { Difference }\end{array}$ \\
& $\mathrm{t}$ & Sig. (2tailed) & Mean Difference & \\
\hline $\begin{array}{l}\text { Right Ear Hearing } \\
\text { Impairment (HI) }\end{array}$ & 4.798 & .000 & 20.34000 & 4.23931 \\
\hline
\end{tabular}

\begin{tabular}{|l|l|c|c|c|c|}
\hline & Group name & $\mathrm{N}$ & Mean & Std. Deviation & $\begin{array}{c}\text { Std. Error } \\
\text { Mean }\end{array}$ \\
\hline \multirow{2}{*}{$\begin{array}{l}\text { Left Ear Hearing } \\
\text { Impairment (HI) }\end{array}$} & Smokers & 50 & 48.4600 & 20.44126 & 2.89083 \\
\cline { 2 - 6 } & $\begin{array}{l}\text { Non } \\
\text { smokers }\end{array}$ & 50 & 26.7200 & 22.54975 & 3.18902 \\
\hline
\end{tabular}

\begin{tabular}{|l|c|c|c|c|}
\hline & \multicolumn{4}{|c|}{ t-test for Equality of Means } \\
\hline \multirow{2}{*}{$\begin{array}{l}\text { Left Ear Hearing } \\
\text { Impairment (HI) }\end{array}$} & $\mathrm{t}$ & Sig. (2-tailed) & $\begin{array}{c}\text { Mean } \\
\text { Difference }\end{array}$ & $\begin{array}{c}\text { Std. Error } \\
\text { Difference }\end{array}$ \\
\cline { 2 - 5 } & 5.051 & .000 & 21.74000 & 4.30427 \\
\cline { 2 - 5 } & & & & \\
\hline
\end{tabular}

\begin{tabular}{|l|l|l|l|l|}
\hline & Mean HI in Rt Ear & Mean HI in Lt Ear & SD of HI in Rt Ear & SD of HI in Lt Ear \\
\hline Smokers & 47.44 & 48.46 & 22.06 & 20.44 \\
\hline Non smokers & 27.10 & 26.72 & 20.29 & 22.54 \\
\hline
\end{tabular}

t test between smokers and non-smokers

tvalue $\quad \mathrm{p}$ value

\begin{tabular}{|l|l|l|}
\hline Right ear & 4.798 & $<0.0001$ \\
\hline Left ear & 5.051 & $<0.0001$ \\
\hline
\end{tabular}

This is highly significant at $0.0001(\mathrm{p}<0.01$ is considered significant) 
Thus smoking associated with deafness is highly significant. Thus student $t$ test is used to evaluate the association of hearing loss between smokers and nonsmokers

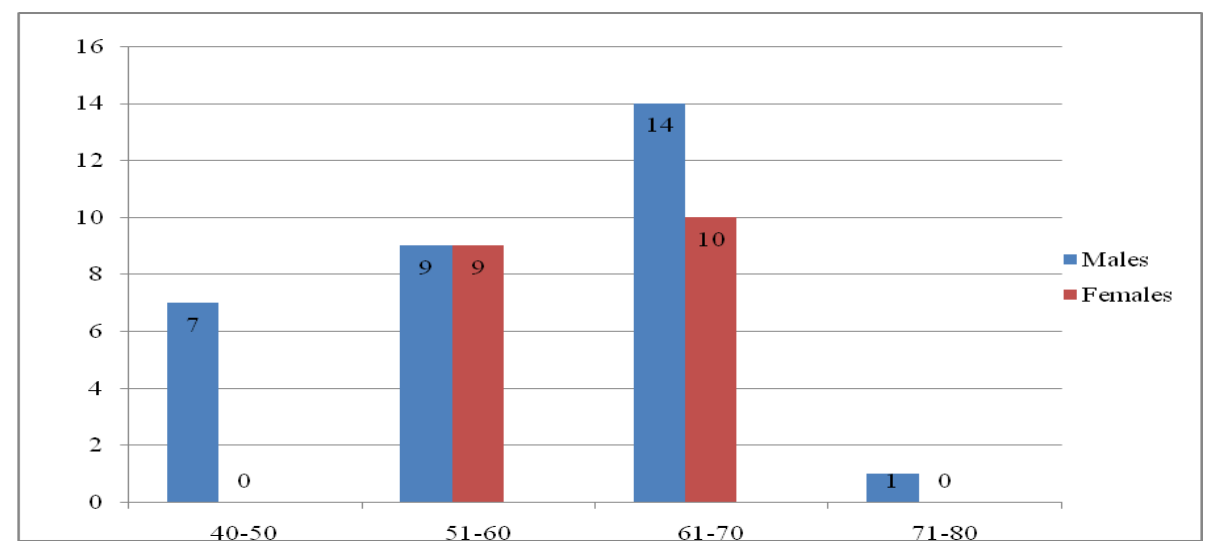

Distribution of male and female smokers according to age group

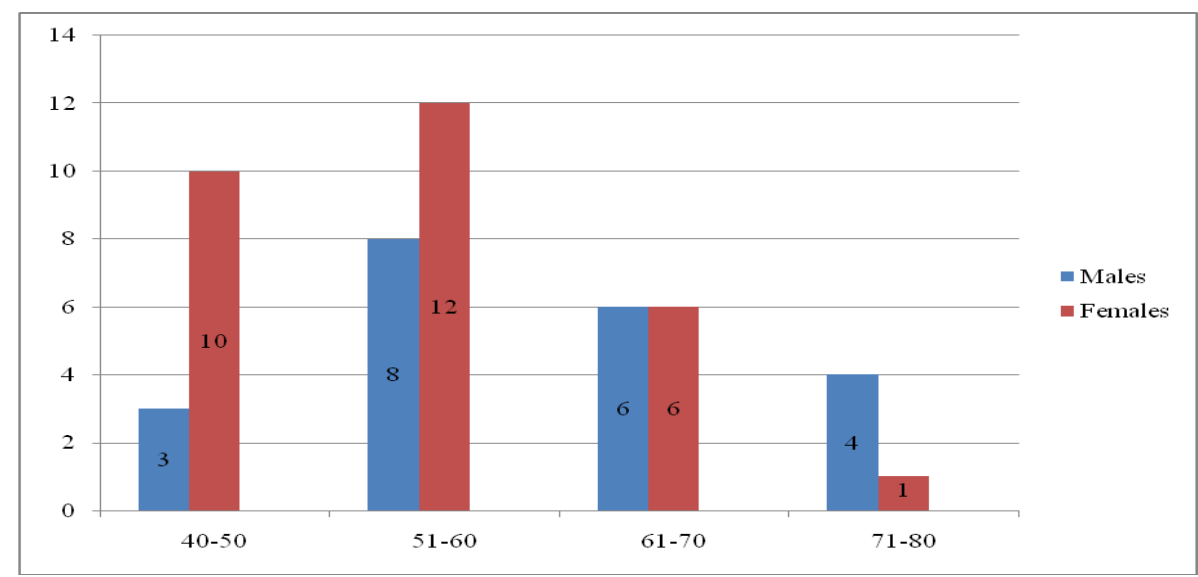

Distribution of male and female Nonsmokers according to age group

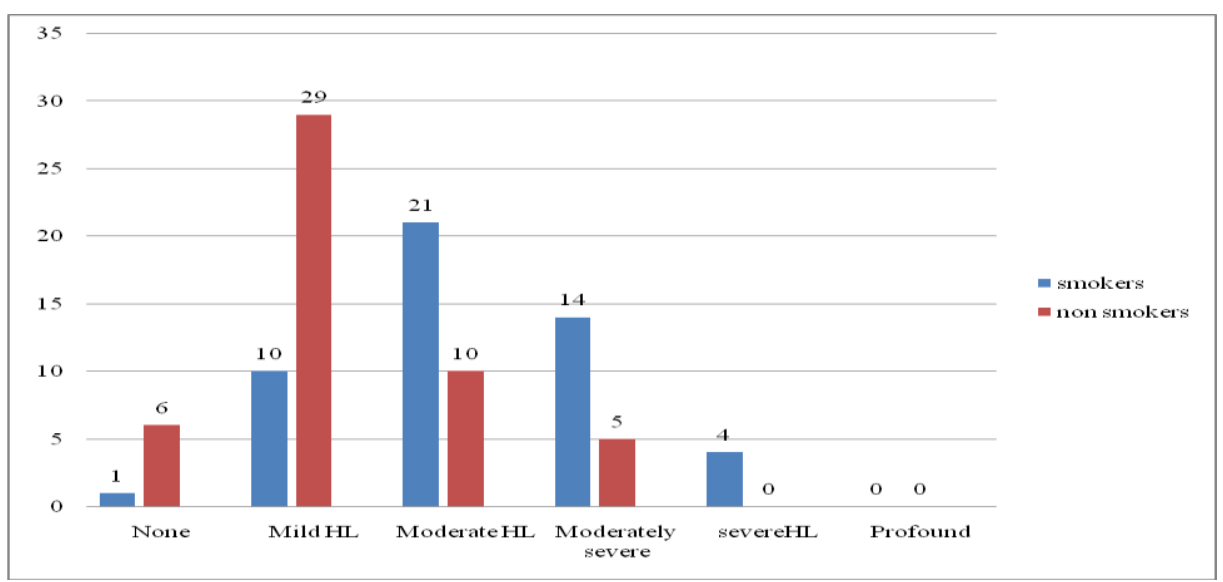

Distribution of smokers and Nonsmokers according to grades of Hearing impairment 


\section{ORIGINAL ARTICLE}

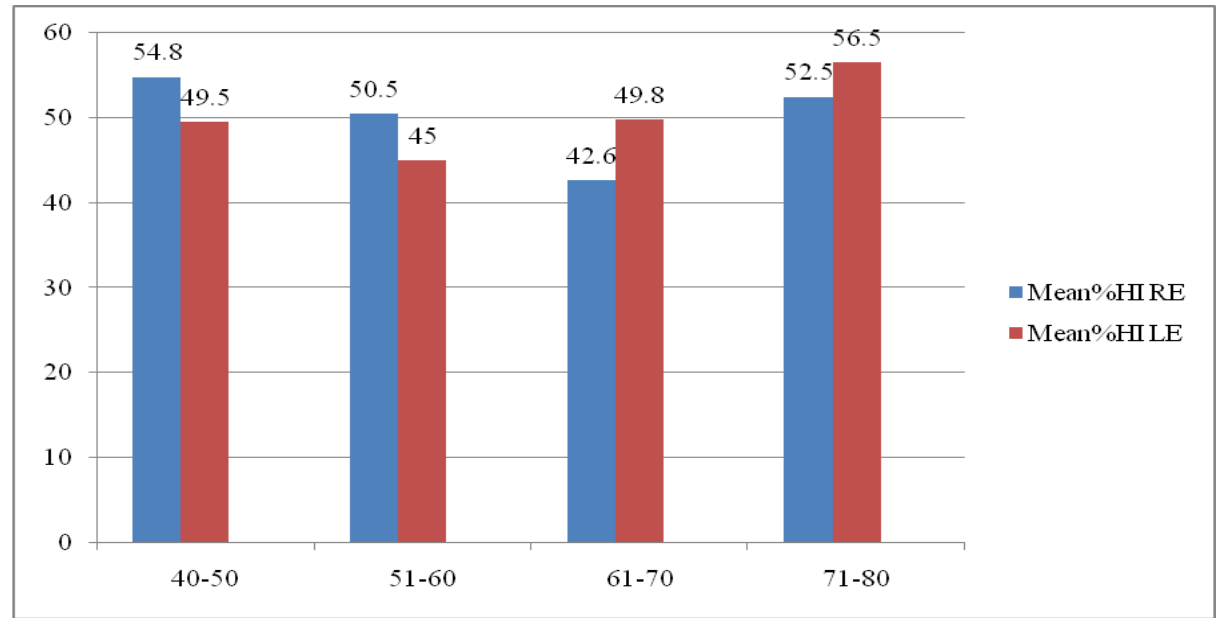

Mean \% Hearing Impairment in Right Ear and Left Ear among Smokers

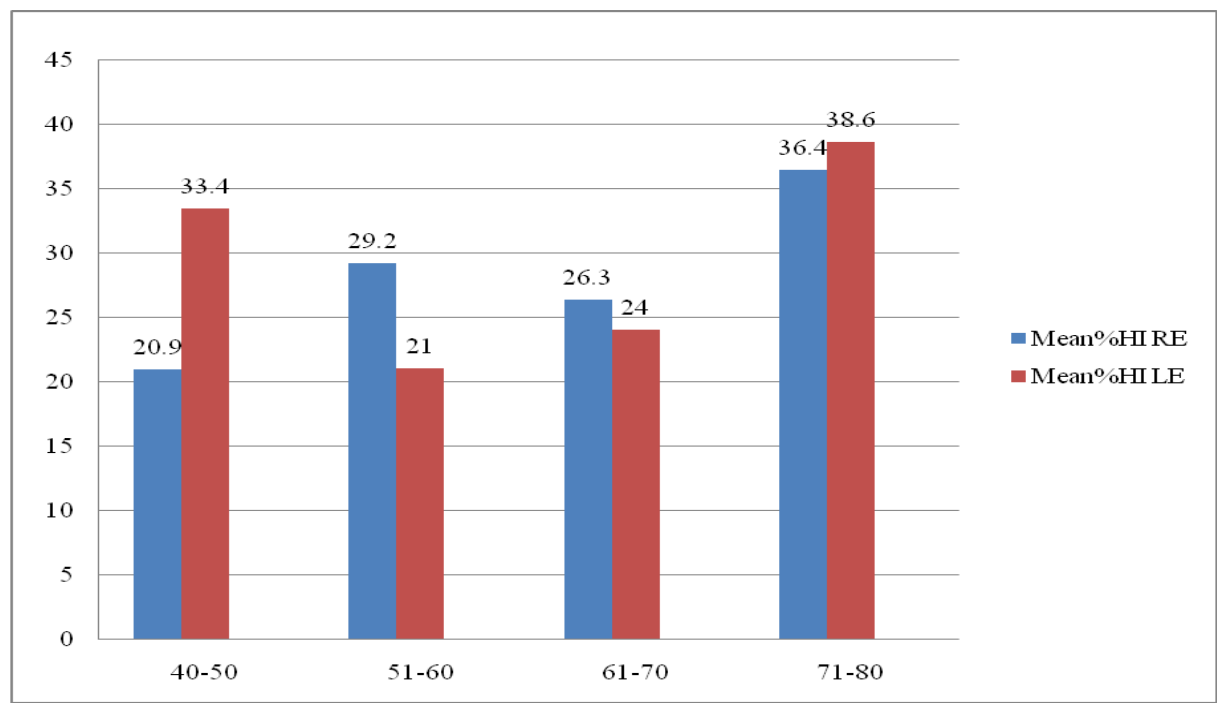

Mean \% Hearing Impairment in Right Ear and Left Ear among Non-smokers

\section{AUTHORS:}

1. P. Pratima,

2. M. Padma Geethanjali,

3. M. Usha Rani

PARTICULARS OF CONTRIBUTORS:

1. Assistant Professor, Department of Physiology-Andhra Medical College, Visakhapatnam, A.P

2. Professor, Department of PhysiologyAndhra Medical College, Visakhapatnam, A.P

3. Associate Professor, Department of Physiology-Andhra Medical College, Visakhapatnam, A.P

\section{NAME ADRRESS EMAIL ID OF THE} CORRESPONDING AUTHOR:

Dr. Pratima,

Assistant Professor, A.M.C,

Visakhapatnam, Andhra Pradesh.

E-mail: pedadapratima23@gmail.com

Date of Submission: 05/07/2013. Date of Peer Review: 05/07/2013. Date of Acceptance: 08/07/2013.

Date of Publishing: 10/07/2013 